A mindfulness parent well-being course: Evaluation of outcomes for parents of children with autism and related disabilities recruited through special schools

Leah Jones

School of Psychology, Bangor University

Bangor, Gwynedd, LL57 2AS, Tel: 01248 382211, email: leah2181@yahoo.co.uk

\title{
Eluned Gold
}

Centre for Mindfulness Research and Practice, School of Psychology, Bangor University Bangor, Gwynedd, LL57 2AS, Tel: 01248 382498, email: eluned.gold@bangor.ac.uk

\section{Vasiliki Totsika}

Tel: 024765 22185, email: v.totsika@warwick.ac.uk

Richard P. Hastings

Tel: 02476 522197, email: R.Hastings@warwick.ac.uk

Centre for Educational Development, Appraisal and Research, University of Warwick Coventry, CV4 7AL

Annee Griffiths (email: mindfulness@bangor.ac.uk), Mariel Jones (email; mariel.jones@bangor.ac.uk) and Sarah Silverton (email: s.silverton@bangor.ac.uk) Centre for Mindfulness Research and Practice, School of Psychology, Bangor University Bangor, Gwynedd, LL57 2AS, Tel: 01248382498

Corresponding author: Dr Leah Jones leah2181@yahoo.co.uk 
Funding: The research reported in this paper was supported through grants from the National Institute for Social Care and Health Research, Wales (grant number SCS/09/11), and the Baily Thomas Charitable Fund (grant number 2546/5066).

Disclosure statement: Eluned Gold developed the mindfulness course evaluated in this study. The authors have no other interests to declare. 


\begin{abstract}
Parents of children with intellectual disabilities and/or autism have been shown to experience higher levels of stress and mental health problems than other parents. Despite such data having been available for several decades, the evidence base for psychological interventions to support parental well-being is small. Recent data suggest that both mindfulness and acceptance processes are associated with decreased psychological distress for parents of children with intellectual disability and/or autism. In addition, some controlled evaluations of mindfulness-based interventions for these parents have resulted in positive outcomes for mothers in particular. In the present study, we recruited 18 mothers and three fathers via special schools who then attended a Mindfulness Based Well-Being for Parents (MBW-P) group for two hours per week for eight weeks. Parents completed questionnaire measures before attending the group and at the end of the course. Statistical analysis using paired t tests showed significant reported increases in mindfulness and self-compassion, and a reduction in general stress, from pre- to post-intervention. Parents also reported reductions in anxiety and depression, although with much smaller effect sizes and these changes were not statistically significant. No significant reductions in their child's behaviour problems or increases in the child's prosocial behaviour were found. Parents also reported high levels of satisfaction with the MBW-P group, with all but one parent reporting that they would recommend the course to others. These preliminary data suggest that further more robustly designed research studies would be worthwhile to test the effectiveness of the MBW-P course to improve parents' psychological well-being.
\end{abstract}

Keywords: Autism, Intellectual Disability, Mothers, Fathers, Mindfulness, Psychological Acceptance 
Population-based research suggests that being a parent is associated with improved psychological well-being (Helbig, Lampert, Klose \& Jacobi, 2006). However, parenting a child with an Intellectual Disability (ID) or an Autism Spectrum Disorder (ASD) has regularly been associated with elevated psychological distress. Data from recent population-based samples demonstrate increased risk for negative well-being outcomes in mothers of children with ID or ASD, and that these differences emerge early (by the time the child is five years old; Totsika, Hastings, Emerson, Berridge \& Lancaster 2011; Totsika, Hastings, Emerson, Lancaster \& Berridge, 2011).

Given that parents of children with intellectual and developmental disabilities (IDD) clearly have significant support needs, researchers have for some time reported evaluations of a variety of parent support interventions. Previous support interventions have tended to focus on increasing functional and adaptive skills in their children and/or decreasing challenging behaviours through behavioural parent training (Crockett et al., 2007; Chadwick, Momcilovic, Rossiter, Stumbles \& Taylor, 2001; Feldman \& Werner, 2002; Gillet \& LeBlanc, 2007; McIntyre, 2008; Solomon et al., 2007; Whittingham, Sofronoff \& Sheffield \&Sanders, 2009). In addition, cognitive behavioural (CBT) techniques (e.g. restructuring cognitive distortions or irrational beliefs) have been used to directly target parental mental health (Gammon \& Rose, 1991; Greaves, 1997; Hastings \& Beck, 2004; Nixon \& Singer, 1993; Singer, Ethridge \& Aldana, 2007).

A difficulty with existing parent interventions is a potential lack of attention to stressors other than the child with IDD, with many parents exposed to a variety of stressors both directly and indirectly associated with their child. Using CBT techniques may not always be appropriate either since many of the stressors experienced may transcend unhelpful cognitions (Singer, 1993). Parents may well benefit from interventions that teach them different ways to respond to potential stressors and that may build a more general resilience. 
Interventions incorporating mindfulness-based techniques have a growing evidence base, and have been shown to decrease psychological distress and improve well-being in a variety of populations. Mindfulness can be described as an awareness which "emerges when we pay attention to experience in a particular way: on purpose (the attention is deliberately placed on particular aspects of experience); in the present moment (when the mind slips into the past or the future we bring it back to the present); and non-judgmentally (the process is infused with a spirit of acceptance of whatever arises)" (Crane, 2009, p. 4). When attending more fully to the present moment individuals are able to generate more response options, and might be described as having greater psychological flexibility (Hayes et al., 2006). Mindfulness is developed through meditation techniques, and although these techniques derive from Buddhist practices, mindfulness in the current context is secular. Jon Kabat-Zinn's eight-week Mindfulness-Based Stress Reduction (MBSR) programme (Kabat-Zinn, 1990) has proved effective in a variety of medical contexts (Grossman et al., 2004; Shigaki et al, 2006), and psychological therapies incorporating mindfulness techniques have a developing evidence base, including Mindfulness-Based Cognitive Therapy (Hofmann, Sawyer, Witt \& Oh, 2010; Teasdale et al., 2000) and Acceptance and Commitment Therapy (Hayes, Strosahl \& Wilson, 1999; Powers, Zum Vörde Sive Vörding \& Emmelkamp, 2009). Mindfulness and acceptance approaches do not focus on trying to change cognitions, but instead encourage noticing clearly and turning towards difficulties as they unfold.

There are data and theoretical publications supporting the potential benefit of mindfulness-based approaches with carers of people with IDD. Psychological process research has suggested that increased acceptance and mindfulness are associated with lower levels of maternal stress (Jones, Hastings, Totsika, Keane \& Rhule, 2014; Lloyd \& Hastings, 2008). Psychological acceptance has also been found to mediate the impact of child behaviour problems on the psychological well-being of mothers (Jones et al., 2014; 
Weiss, Cappadocia, MacMullin, Viecili, \& Lunsky, 2012) and fathers (Jones et al., 2014; MacDonald, Hastings \& Fitzsimons, 2010) of children with IDD. These correlational findings suggest that interventions aimed at developing mindfulness and acceptance skills in this population of parents may be effective in improving their well-being.

Emerging data do indeed suggest positive effects of mindfulness and acceptancebased interventions for parents of children with IDD. Blackledge and Hayes (2006) reported improvements in the well-being of parents of children with autism following a two-day ACT workshop. Singh and colleagues $(2006$; 2007) have found mindfulnessbased support delivered to parents of children with ASD/ID on a one-to-one basis to improve parental well-being and child behaviour problems.

In four recent studies, researchers evaluated mindfulness-based support interventions for parents of children with IDD delivered in a group format. In a randomized wait-list controlled trial Benn, Akiva, Arel and Roeser (2012) found parents' stress and distress reduced following an intensive 5 week mindfulness course (with parents receiving 36 hours of training over the duration of the course). Increased mindfulness was shown to mediate the impact of mindfulness training on reduced negative outcomes. In a pilot randomized trial, Ferraioli and Harris (2013) also found improvements in parents' stress and global health levels following mindfulness-based support. Neece (2014) reported results from a small waiting list controlled randomized study evaluating standard MBSR for parents of children with IDD. Parenting stress and depression decreased in the MBSR group, and life satisfaction increased. However, very few changes in child behaviour problems were found. Finally, Dykens et al. (2014) randomized 243 mothers of children of any age with IDD to receive MBSR or a positive psychology intervention. Both interventions were delivered by parents who had children with IDD who were trained in the intervention and received supervision during 
delivery. Outcomes in favour of MBSR included improved maternal anxiety, depression, sleep and well-being. Child outcomes were not reported.

The aim of the current research was to carry out a pilot evaluation of an eightweek Mindfulness-Based Well-Being Course for Parents (MBW-P), with parents of children with ASD and/or ID, by investigating whether parental negative and positive outcomes improved following intervention, and whether child behaviour problems would subsequently improve. The present study differs from the four existing studies (Benn et al., 2012; Dykens et al., 2014; Ferraioli \& Harris, 2013; Neece, 2014), and aims to complement our existing knowledge about the potential utility of mindfulness-based interventions with this population. Benn et al. (2012) implemented a mindfulness-based course for parents and educators of children with developmental delays, with the same curriculum delivered to both groups, and therefore not specifically designed for parents. Neece (2014) and Dykens et al. (2014) evaluated a generic mindfulness intervention without being clear whether adaptations were made for parents of children with IDD. Dykens et al. (2014) also used parents trained to deliver MBSR rather than established mindfulness teachers. Although Ferraioli and Harris (2013) did implement a course designed specifically, or adapted, for parents the evaluation of mindfulness-based courses for parents of children with IDD is in its infancy, and the current study is the first of its kind implemented outside of the USA.

Method

\section{Participants}

Twenty-one participants completed the study - three fathers and 18 mothers (including one mother-father couple). Nineteen of the participants were biological parents, and two were adoptive mothers. Seventeen of the participants were married or 
living with a partner and four participants were divorced, single or widowed.

Participants were on average 45 years of age $(S D=6.48)$, and all participants described themselves as being of White-British ethnicity. The majority of participants $(N=15)$ were educated below university degree level, and 16 participants were currently in employment. Median household income was $£ 25,000$ - $£ 35,000$ per year (British pounds sterling, approximately $\$ 39,000$ - $\$ 55,000$ US Dollars).

Parents reported on their child's characteristics, including what diagnostic label their children had received, length of time since receiving the diagnosis, and details of who provided the diagnosis. Sixteen children had a diagnosis within the autism spectrum, one child had Down syndrome, two children had Cerebral Palsy, and two were diagnosed with a general intellectual disability. Children had received their diagnoses on average 5 years previously ( $S D=4.50$ years). Thirteen of the children were male and 8 were female. Children were on average 10.53 years of age $(S D=3.16$, range 4 to 16) at the start of the study. Fourteen of the children attended a Special School, five children were in mainstream school with additional support, and two children were in mainstream school without additional support. All children lived at home with their parent(s), and most $(N=14)$ had at least one sibling. All of the children scored within the range typical of children with ID on a measure of global adaptive functioning (the Vineland Adaptive Behavior Scales, Adaptive Behavior Composite standard score) or within error limits $(M=59.43, S D=5.64$, range 51-72). Thus, all of the children experienced significant developmental delay.

\section{Measures}

Participants completed a set of questionnaires at two time points: preintervention (T1) and post-intervention (T2). At T1, participants completed a consent form, a demographics questionnaire to collect the information described above, as well 
as the primary outcome measures measuring their child's behaviour, their own positive and negative psychological well-being (general and child-related), and psychological process questionnaires. At T2, participants completed the same primary outcome measures as T1 and a brief questionnaire rating satisfaction with different aspects of the MBW-P course. Participants also completed a measure of their child's adaptive functioning, in the form of a semi-structured interview, over the telephone, as a baseline measure only at T1.

\section{Child measures}

The Vineland Adaptive Behavior Scales - 2nd Edition (VABS II; Sparrow, Cicchetti \& Balla, 2005) was used as a measure of the child's adaptive functioning. The VABS II is administered as a semi-structured interview, and was conducted over the telephone. The VABS II consists of items arranged in developmental sequence, measuring behaviours across four domains: socialization, communication, daily living skills and motor skills (motor skills domain only administered to children below the age of 7). An overall adaptive behaviour composite score was used to confirm children's developmental delay.

The Strengths and Difficulties Questionnaire (SDQ; Goodman, 1997) was used to measure children's prosocial behaviour and behavioural difficulties. The SDQ is a wellvalidated and widely used 25 -item scale measuring behavioural and emotional adjustment across five domains: a prosocial behaviour domain and four problem behaviour domains (emotional symptoms, conduct problems, hyperactivity, and peer problems). Respondents rate statements about their child as either not true, somewhat true, or certainly true. Example items include "Nervous or clingy in new situations, easily loses confidence” (emotional symptoms); “Often lies or cheats” (conduct problems); 
"Restless, overactive, cannot stay still for long" (hyperactivity); "Rather solitary, tends to play alone" (peer problems); “Helpful if someone is hurt, upset or feeling ill” (prosocial behaviour). A total difficulties score is generated by summing the scores of the four problem behaviour domains. When previously used with parents of children with IDD the SDQ has displayed good internal consistency for both the prosocial behaviour (Cronbach's $\alpha=.85$ ) and total difficulties subscales (Cronbach's $\alpha=.82$ ) (MacDonald et al., 2010).

\section{Parental measures}

To measure psychological distress at a general level, the Hospital Anxiety and Depression Scale (HADS; Zigmond \& Snaith, 1983) was used. The 14-item tool was originally constructed to allow quick measurement of generalized anxiety and depression in hospital settings, but has since been used widely in community research, including with parents of children with autism and other disabilities. Seven items measure each construct, generating subscales scores, which were used in the current research. Respondents rate statements on a four-point scale, for example "I get a sort of frightened feeling as if something awful is about to happen" is rated as either very definitely and quite badly, yes, but not too badly, a little, but it doesn't worry me, or not at all; and "I feel as if I am slowed down" is rated as either most of the time, a lot of the time, from time to time, or not at all. The measure has shown good reliability when previously used with parents of children with IDD (MacDonald et al., 2010) with internal consistency (Cronbach's $\alpha$ ) of .88 for the anxiety subscale, and .83 for the depression subscale.

We used the stress subscale from the Depression Anxiety Stress Scale (Lovibond \& Lovibond, 1995; Short Form) to measure general stress. The 21-item scale measures the three negative emotional states, with seven items measuring each construct. Good 
psychometric properties have previously been obtained, and the scale has previously been used in mindfulness-based intervention research (Ree \& Craigie, 2007). We used only the seven items measuring general stress, as depression and anxiety were measured using the HADS. Respondents rated how statements such as "I felt I was rather touchy" and "I found it hard to wind down" applied to them over the preceding week, as either did not apply to me at all, applied to me to some degree, or some of the time, applied to me a considerable degree, or a good part of the time, or applied to me very much, or most of the time. The scale has shown good levels of internal consistency in a previous study of parents of children with IDD (Cronbach's $\alpha=.94$; Plant \& Sanders, 2007).

The Parent and Family Problems Subscale of The Questionnaire on Resources and Stress-Short Form (QRS-F; Friedrich, Greenberg \& Crnic, 1983) was used to measure general parenting stress associated with the child with ID/ASD. The 20-item measure includes five items relating to depression (Gidden \& Floyd, 1997), which were excluded from analysis in the current study to avoid measurement overlap, as depression was measured separately with the HADS. Respondents rated the remaining 15 items as true or false. Example items include "There is a lot of anger and resentment in our family" and "In the future, our family's social life will suffer because of increased responsibilities and financial stress". The QRS-F has previously been used in research with parents of children with ASD, with good reliability (Kuder-Richardson coefficient = .90; MacDonald et al., 2010).

The positive affect subscale from the Positive and Negative Affect Scale (PANAS; Watson et al., 1988) was used as a measure of general positive psychological well-being. Respondents rate to what extent ten items, including "Interested”, “Alert", "Inspired”, and "Enthusiastic" have applied to them during the past week, on a scale from very slightly or not at all, a little, moderate, quite a bit, to extremely. The scale was chosen for 
the current study because of its briefness to administer, and previous use with this population of parents with good reliability (Cronbach's $\alpha=.92$; Griffith et al., 2011).

The Positive Gain Scale (PGS; Pit-ten Cate, 2003) is a seven-item tool measuring positive perceptions relating to parenting a child with a disability, with items measuring perceived benefits to parents personally, and as a family. Respondents choose whether they strongly agree, agree, not sure, disagree, or strongly disagree with statements such as "Since having this child I feel I have grown as a person" and "Since having this child, my family has become more tolerant and accepting". Lower scores on the PGS indicate higher levels of positivity. High internal consistency has previously been obtained with parents of children with IDD (Cronbach's $\alpha=.87$; Jones et al., 2014).

\section{Process measures}

General dispositional mindfulness was measured using the Five Facets Mindfulness Questionnaire (FFMQ; Baer, Smith, Hopkins, Krietemeyer \& Toney, 2006). The FFMQ is a well-validated 39-item instrument, measuring a general tendency to be mindful in day-to-day life. The FFMQ measures five underlying constructs of mindfulness (Baer et al., 2006): observing (noticing experiences), describing (labeling experiences with words), acting with awareness (deliberately attending to moment-tomoment behaviours and activities), non-reactivity (to inner experience), and accepting without judgment (taking a non-evaluative stance towards inner experience). Respondents rate statements as either never or very rarely true, rarely true, sometimes true, often true, or very often or always true. Example items include: "I notice how foods and drinks affect my thoughts, bodily sensations, and emotions." (observe); "My natural tendency is to put my experiences into words" (describe); "I find myself doing things without paying attention" (acting with awareness); "In difficult situations, I can pause without immediately reacting” (non-reactivity); "I criticize myself for having irrational 
or inappropriate emotions." (non-judging). The FFMQ has shown good psychometric properties when used with a variety of populations, including meditating and nonmeditating samples (Baer et al., 2008). Five subscale scores can be derived from the scale, and a total score, which was used in the current study. The measure has displayed good internal consistency when previously used with parents of children with IDD $(\alpha=.93 ;$ Jones et al., 2014).

The Bangor Mindful Parenting Scale (BMPS; Jones et al., 2014) was used as a measure of situational mindfulness in the parenting context. The BMPS is a 15-item instrument, based on items selected from the FFMQ amended to relate specifically to parenting, generating a total score representing a general tendency to be mindful whilst parenting. Respondents rate items as either never true, sometimes true, often true, or always true, with example items including: "I rush through activities with my child without being really attentive to him/her", "I pay attention to how my emotions affect the way I act towards my child", "When I get upset with my child I am able to keep calm", and "I think some of my emotions towards my child are bad and I shouldn't be feeling them". Internal consistency (Cronbach's $\alpha$ ) obtained in a previous study with parents of children with IDD was .79 (Jones et al., 2014).

The Acceptance and Action Questionnaire-Intellectual Disability Parent version (AAQ-ID; MacDonald et al., 2010) was used in the current study to measure psychological acceptance in relation to parenting a child with ASD/ID. The AAQ-ID is an eight-item tool adapted from the 'Acceptance and Action Questionnaire-II' (Bond et al., 2011), with items re-worded to refer specifically to children with a disability. Respondents rate statements on a 7-point scale, ranging from never true to always true. Example items include "I'm afraid of my feelings about my child with ASD/ID" and "I worry about not being able to control my worries and feelings about my child with 
ASD/ID". When used in a previous study of parents of children with IDD the measure displayed good internal consistency (Cronbach's $\alpha$ ) of .80 (MacDonald et al., 2010).

The Self-Compassion Scale-Short Form (Raes, Pommier, Neff \& Van Gucht, 2011) was used to assess a construct related to mindfulness that was a theme within the intervention. The Short Form was selected for inclusion because of its brevity and near perfect correlation with the original long form (Raes et al, 2011). Respondents rate items such as: "When I fail at something important to me I become consumed by feelings of inadequacy" and "I try to see my failings as part of the human condition" on a fivepoint scale, ranging from almost never to almost always. To our knowledge the scale has not previously been used with parents of children with IDD but internal consistency (Cronbach's $\alpha$ ) in the current study was .87.

\section{Procedure}

The Research Ethics and Governance Panel at Bangor University approved the study protocol. Three schools in North Wales agreed to host a MBW-P course each on their premises (one specialist autism school, and two general intellectual disability special schools). Invitations were sent to parents through the schools. Invitations were also extended to parents of children with ASD and/or ID attending other local schools within the vicinity, advertising via charities and word of mouth. Invitation packs distributed included a Participant Information Sheet outlining the research, a Course Information Sheet briefly outlining the content of the MBW-P course, and a Contact Form for people to complete and return to the team in a prepaid envelope if they were interested in attending. Self-referrals were also accepted. When Contact Forms were returned to the team, prospective participants were contacted by telephone by the first author to discuss the MBW-P course in more detail. All participants were invited and encouraged to attend an orientation session before the eight-week course began. The 
orientation session was an opportunity for attendees to meet each other, to meet the mindfulness teacher, and to experience a short mindfulness meditation practice. If participants were unable to attend the orientation session, the mindfulness teacher contacted them by telephone before the MBW-P course began. Approximately 300 invitation packs were distributed, with 30 parents showing an initial interest. Five of the initial enquirers decided not to participate and 25 began the course. Four individuals across the three intervention groups formally dropped out of the study after attending an average of two sessions. None of these four parents provided T2 data. Their reasons for not completing the course were the time commitment (x3) and family bereavement.

Participants were given the T1 Questionnaire Pack either during the Orientation Session (if they were present) to complete at home and return in a prepaid envelope, or they were mailed the Questionnaire Pack a week before the intervention began. Participants were provided with the T2 Questionnaire Pack at the end of the final session, asked to complete it as soon as possible, and return it to the research team in the prepaid envelope provided. At T2 all questionnaire packs were returned for the 21 parents who completed the course.

\section{Description of the MBW-P Intervention}

The mindfulness training program delivered in the current study was a new Mindfulness-Based Well-Being Course for Parents (MBW-P), developed by the Centre for Mindfulness Research and Practice (CMRP), Bangor University, UK. The MBW-P follows an eight-week format with participants attending two-hour sessions on a weekly basis with home practices each week (similar to MBSR and Mindfulness-Based Cognitive Therapy). The primary aim of the program is to increase participants' mindful awareness, whilst recognizing the shared experiences and difficulties encountered by different groups of parents. Each weekly session included mindfulness practice 
exercises, periods to reflect on the practices (inquiry) as a group and in pairs, orientation to the home practices set for the following week, and reflection on home practices from the previous week.

This particular group of parents is likely to be multiply-stressed and it was therefore anticipated that parents may struggle to find time to engage in lengthy practices between classes. Given the importance of practicing mindfulness techniques between the classes and attempting to incorporate mindfulness techniques into daily life, participants were provided with a CD of short practices ranging in length from five to 20 minutes, as opposed to the more standard 30-45 minute practices seen in other programs. As well as the CD practices, home practices included bringing mindful awareness to routine daily tasks, to communications, and to reactivity patterns. Participants were also encouraged to engage in nurturing activities, by being kind to themselves and making time to engage in an activity they enjoyed. Table 1 presents an overview of the weekly classes and the home practices.

The mindfulness teacher and was available to support participants over the telephone between sessions if participants felt the need. The mindfulness teacher would also contact any participant who may have become upset or distressed during any of the sessions. The mindfulness teachers who delivered the MBW-P intervention groups are employed by the CMRP, are experts in their field, and all met rigorous criteria for competence in delivering mindfulness-based interventions described by Crane et al. (2012). The CMRP has been delivering mindfulness courses for over ten years, with teachers trained and supervised by expert teachers at the Centre for Mindfulness Massachusetts, where courses have been delivered for 30 years. 
Completer analyses were conducted. Paired-samples $t$-tests compared participants' pre and post-treatment scores on all measures. Effect sizes were calculated and interpreted using Cohen's $d$. Given the relatively small sample, analyses were repeated using Wilcoxon tests as a non-parametric equivalent to the t-test. No differences in the pattern of results were obtained and so only the t-test results are reported.

Significant differences pre-post intervention were found for measures of general mindfulness $(p=.008)$, self-compassion $(p=.039)$, and general stress $(p=.031)$, with participants reporting increased mindfulness and self-compassion, and decreased general stress over time. Table 2 displays mean scores on all measures at $\mathrm{T} 1$ and $\mathrm{T} 2$, the results of the pre-post comparisons, and effect sizes. When interpreting effect sizes, Cohen (1992) suggested $d=0.2$ be considered a small effect size, 0.5 a medium effect size and 0.8 a large effect. Medium effects were found in relation to increased general mindfulness $(d=0.49)$ and reduced general stress $(d=0.49)$, with small effects for improvements in positive gain $(d=0.31)$, increased self-compassion $(d=0.39)$, reductions in anxiety $(d=0.26)$ and reductions in depression $(d=0.21)$.

Given that 16 of the 21 participants were parenting children reported to have a diagnosis of ASD, analyses were repeated for this subgroup of parents alone. The same overall pattern of results was obtained. Some differences were found when interpreting significance levels of the $t$-test results for the ASD parent subgroup: a significant increase in general mindfulness levels was still observed $(p=.029)$, with improvements in self-compassion $(p=.055)$ and general stress $(p=.109)$ no longer reaching statistical significance at the .05 level. However, an increase in positive gain for these parents was approaching significance $(p=.055)$ which had not been the case for the entire sample's data $(p=.151)$. Although some differences were observed when comparing significance levels, effect sizes were similar for both the subgroup of parents and the overall sample. 
Participants also completed a brief Satisfaction Questionnaire post-intervention. Table 3 displays participants' satisfaction ratings with different aspects of the MBW-P course.

\section{Discussion}

Participants' self-reported levels of general mindfulness and self-compassion significantly increased following the MBW-P course. Significant improvements were also reported for parents' general stress levels. Family level stress was also measured, but no statistically significant or meaningful levels of change were observed. Results were also less robust in terms of the other outcomes measures.

Although not at statistically significant levels, improvements (albeit small) were found when interpreting effect sizes of changes in scores on anxiety, depression and positive gain measures, and given the small sample in the current study statistical significance alone is not a meaningful measure of change in outcome. In relation to the small change in depression scores, the small effect may not necessarily be due to a lack of treatment effect, but possibly because of relatively moderate levels of depression presented by the current sample, with a pre-intervention mean scores of 6.75 , and a recommended cut-off score for clinical levels of depression suggested at 10/11 (Crawford, Henry, Crombie, \& Taylor, 2001).

As well as measuring stress at a parent-child/familial level, we also measured mindfulness specifically in the parenting context. No significant or meaningful changes were observed in participants' levels of mindfulness whilst parenting. Given that general dispositional mindfulness increased following intervention, and general levels of stress reduced, a lack of improvement in child-related stress may be due to an absence of enhanced mindfulness in the parenting context.

Although the mindfulness intervention was designed for parents by recognizing parents' shared experiences and difficulties, the intervention's main intention was to 
increase participants' mindful awareness at a general level, which was achieved. The results suggest that to target child-related stress more focus should be placed on increasing mindfulness skills specifically in the parenting context. It was hoped that equipping parents with general mindfulness skills would enable parents to utilize these skills across varying contexts, given the multiple stressors parents often experience. Child behaviours were also measured, to investigate whether child behaviours would be indirectly affected. No changes in child behaviours were observed immediately following the intervention.

The current study has a number of methodological weaknesses that need to be considered when drawing inferences from the results. There was no comparison group. Therefore, it is difficult to conclude whether the improvements in well-being observed are a result of the mindfulness intervention, and not effects of attending a group and developing a greater support network. Future research should include an active control condition of some kind that also includes group support aspects. It was also difficult to track engagement in home practice. Participants were provided with a Home Practice Record Sheet each week to track their mindfulness activities on a daily basis, however, completion rates of the form was very low (at approximately 30\%) and it is difficult to conclude whether this represents a lack of engagement in the home practice, or the impracticality of completing a record form.

The MBW-P intervention was a new course for parents of children with IDD, evaluated for the first time in the current study. Different mindfulness teachers delivered each intervention group, and although the program was manualized, treatment fidelity data were not collected. A well-established mindfulness program may have been more effective. Future research is needed to compare different mindfulness programs whilst controlling for the effects of peer/group support. The current sample scored moderately on the negative well-being measures thus it is questionable whether 
we recruited the most hard-to-reach parents who may be more negatively affected and in need of support. It is also important to note that, as well as being a relatively small sample of 21 parents overall, only three of these were fathers. Therefore, it is not appropriate to infer positive outcomes for fathers generally following the mindfulness course.

Efforts were made to make the course as accessible as possible, with courses delivered during school hours so parents would not have to arrange child care (unless they had younger children who were not attending school), and financial assistance was available for parents who would not be able to attend otherwise (up to $£ 10$ per session towards the cost of child care or travel to the classes). However, it is unclear whether the parents recruited are representative of the typically highly-distressed parents frequently reported in the literature. Participants volunteered for the current study, and this self-selection recruitment procedure may have produced a biased sample of parents who are actively engaged with/seeking support services. In future, referrals by social/health professionals could help recruit parents who are experiencing greater distress, and provide a more representative sample of parents - at least those known to services. In future replications, it will also be important to investigate whether any changes are maintained or even increased over time (e.g., relating to continued mindfulness meditation practice).

The majority of parents rated the course very positively and all but one would definitely recommend course to others parents in similar a situation to themselves, suggesting parents clearly feel they benefitted, and the eight-week format was accessible to this particular group. Considering the small sample size in the study, the results support the potential utility of mindfulness-based support for parents whilst highlighting a need for further controlled trials of mindfulness interventions for parents of children with ASD and other disabilities. 


\section{References}

Baer, R. A., Smith, G. T., Hopkins, J., Krietemeyer, J., \& Toney, L. (2006). Using self-report assessment methods to explore facets of mindfulness. Assessment, 13(1), 27-45. doi: $10.1177 / 1073191105283504$

Baer, R. A., Smith, G. T., Lykins, E., Button, D., Krietemeyer, J., Sauer, S., . . Williams, J. M. G. (2008). Construct validity of the five facet mindfulness questionnaire in meditating and non-meditating samples. Assessment, 15(3), 329-342. doi: $10.1177 / 1073191107313003$

Benn, R., Avika, T., Arel, S., \& Roeser, R. W. (2012). Mindfulness training effects for parents and educators of children with special needs. Developmental Psychology, 48 (5), 1476-1487. doi: 10.1037/a0027537

Blackledge, J. T., \& Hayes, S. C. (2006). Using acceptance and commitment training in the support of parents of children diagnosed with autism. Child \& Family Behavior Therapy, 28(1), 1-18. doi: 10.1300/J019v28n01_01

Bond, F. W., Hayes, S. C., Baer, R. A., Carpenter, K. M., Guenole, N., Orcutt, H. K., ... Zettle, R. D. (2011). Preliminary psychometric properties of the acceptance and action Questionnaire-II: A revised measure of psychological inflexibility and experiential avoidance. Behavior Therapy, 42(4), 676-688. doi: 10.1016/j.beth.2011.03.007

Chadwick, O., Momcilovic, N., Rossiter, R., Stumbles, E., \& Taylor, E. (2001). A randomized trial of brief individual versus group parent training for behaviour problems in children with severe learning disabilities. Behavioural and Cognitive Psychotherapy, 29, 151-167. doi:10.1017/S135246580100203X 
Cohen, J. (1992). A power primer. Psychological Bulletin, 112(1), 155-159. doi: 10.1037/0033-2909.112.1.155

Crane, R. (2009). Mindfulness-Based Cognitive Therapy: Distinctive Features. London: Routledge.

Crane, R. S., Kuyken, W., Williams, J. M. G., Hastings, R. P., Cooper, L., \& Fennell, M. J. V. (2012). Competence in teaching mindfulness-based courses: Concepts, development, and assessment. Mindfulness, 3, 76-84. doi: 10.1007/s12671-0110073-2

Crawford, J. R., Henry, J. D., Crombie, C., \& Taylor, E. P. (2001). Normative data for the HADS from a large non-clinical sample. British Journal of Clinical Psychology, 40 (4), 429-434. doi: 10.1348/014466501163904.

Crockett, J. L., Fleming, R. K., Doepke, K. J., \& Stevens, J. S. (2007). Parent training: Acquisition and generalization of discrete trials teaching skills with parents of children with autism. Research in Developmental Disabilities, 28(1), 23-36. doi: 10.116/j.ridd.2005.10.003

Dykens, E. M., Fisher, M. H., Taylor, J. L., Lambert, M., \& Miodrag, N. (2014). Reducing distress in mothers of children with autism and other disabilities: A randomized trial. Pediatrics, 134, e454-e463. doi: 10.1542/peds.2013-3164

Ferraioli, S. J., \& Harris, S. L. (2013). Comparative effects of mindfulness and skill-based parent training programs for parents of children with autism: Feasibility and preliminary outcome data. Mindfulness, 4 (2), 89-101. doi: 10.1007/s1267-0120099-0 
Feldman, M. A., \& Werner, S.E. (2002). Collateral effects of behavioral parent training on families of children with developmental disabilities and behavior disorders. Behavioral Interventions 17, 75-83. doi: 10.1002/bin.111

Friedrich, W. N., Greenberg, M. T., \& Crnic, K. (1983). A short-form of the questionnaire on resources and stress. American Journal of Mental Deficiency, 88(1), 41-48.

Gammon, E.A., \& Rose, S.D. (1991). The Coping Skills Training Program for parents of children with developmental disabilities: An experimental evaluation. Research on Social Work Practice, 1, 244-256.

Glidden. L. M., \& Floyd, F. J. (1997). Disaggregating parental depression and family stress in assessing families of children with developmental disabilities: A multi-sample analysis. American Journal on Mental Retardation, 102(3), 250-266.

Gillett, J. N., \& LeBlanc, L. A. (2007). Parent-implemented natural language paradigm to increase language and play in children with autism. Research in Autism Spectrum Disorders, 1(3), 247-255. doi: 10.1016/j.rasd.2006.09.003

Greaves, D. (1997). The effect of rational-emotive parent education on the stress of mothers of young children with Down syndrome. Journal of Rational-Emotive and Cognitive-Behavior Therapy, 15, 249-267. doi: 10.1023/A:1025063425172

Goodman, R. (1997). The strengths and difficulties questionnaire: A research note. Journal of Child Psychology and Psychiatry and Allied Disciplines, 38(5), 581-586. doi: 10.1111/j.1469-7610.1997.tb01545.x

Griffith, G. M., Hastings, R. P., Oliver, C., Howlin, P., Moss, J., Petty, J., \& Tunnicliffe, P. (2011). Psychological well-being in parents of children with Angelman, Cornelia de 
Lange and Cri du Chat syndromes. Journal of Intellectual Disability Research, 55(4), 397-410. doi: 10.1111/j.1365-2788.2011.01386.x

Grossman, P., Niemann, L., Schmidt, S., \& Walach, H. (2004). Mindfulness-based stress reduction and health benefits: A meta-analysis. Journal of Psychosomatic Research, 57(1), 35-43. doi: 10.1016/S0022-3999(03)00573-7

Hastings, R. P., \& Beck, A. (2004). Stress intervention for parents of children with intellectual disabilities. Journal of Child Psychology and Psychiatry, 45, 1338-1349. doi: 10.1111/j.1469-7610.2004.00357.x

Hayes, S. C., Strosahl, K. D., \& Wilson, K. G. (1999). Acceptance and commitment therapy: An experiential approach to behavior change. New York: Guildford Press Hayes, S. C., Luoma, J. B., Bond, F. W., Masuda, A., \& Lillis, J. (2006). Acceptance and commitment therapy: Model, processes, and outcomes. Behaviour Research and Therapy, 44, 1-25. doi: 10.1016/j.brat.2005.06.006

Helbig, S., Lampert, T., Klose, M., \& Jacobi, F. (2006). Is parenthood associated with mental health? Findings from an epidemiological community survey. Social Psychiatry and Psychiatric Epidemiology, 41, 889-896. doi: 10.1007/s00127-0060113-8

Hofmann, S. G., Sawyer, A. T., Witt, A. A., \& Oh, D. (2010). The effect of mindfulness-based therapy on anxiety and depression: A meta-analytic review. Journal of consulting and clinical psychology, 78(2), 169. doi: 10.1037/a0018555

Jones, L., Hastings, R. P., Totsika, V., Keane, L., \& Ruhle, N. (2014). Child behavior problems and parental well-being in families of children with Autism: the mediating role of mindfulness and acceptance. American Journal on Intellectual 
and Developmental Disabilities. 119 (2), 171-185. doi: 10.1352/1944-7558119.2.171

Jones, L., Totsika, V., Hastings, R. P., \& Petalas, M. A. (2013). Gender differences when parenting children with Autism Spectrum Disorders: a multilevel modeling approach. Journal of Autism and Developmental Disorders, 43, 2090-2098. doi: 0.1007/s10803-012-1756-9

Kabat-Zinn, J. (1990). Full catastrophe living: Using the wisdom of your body and mind to face stress, pain, and illness. New York: Dell Publishing

Lloyd, T., \& Hastings, R. P. (2008). Psychological variables as correlates of adjustment in mothers of children with intellectual disabilities: Cross-sectional and longitudinal relationships. Journal of Intellectual Disability Research, 52, 37-48. doi: 10.1111/j.1365-2788.2007.00974.x

Lovibond, P. F., \& Lovibond, S. H. (1995). The structure of negative emotional states: Comparison of the Depression Anxiety Stress Scales (DASS) with the Beck Depression and Anxiety Inventories. Behaviour Research and Therapy, 33 (3), 335-343. doi: 10.1016/0005-7967(94)00075-U

MacDonald, E. E., Hastings, R. P., \& Fitzsimons, E. (2010). Psychological acceptance mediates the impact of the behaviour problems of children with intellectual disability on fathers' psychological adjustment. Journal of Applied Research in Intellectual Disabilities, 23(1), 27-37. doi: 10.1111/j.1468-3148.2009.00546.x

McIntyre, L. L. (2008). Adapting Webster-Stratton's incredible years parent training for children with developmental delay: findings from a treatment group only study. Journal of Intellectual Disability Research, 52 (12), 1176-1192. doi: 10.1111/j.1365-2788.2008.01108.x 
Neece, C. L. (2014). Mindfulness-Based Stress Reduction for parents of young children with developmental delays: Implications for parental mental health and child behavior problems. Journal of Applied Research in Intellectual Disabilities, 27, 174186. doi: $10.1111 /$ jar.12064

Nixon, C.D., \& Singer, G.H.S. (1993). Group cognitive- behavioral treatment for excessive parental self- blame and guilt. American Journal on Mental Retardation, 97, 665-672.

Pit-ten Cate, I. M. (2003 unpublished). Family adjustment to disability and chronic illness in children. Unpublished Doctoral Thesis, University of Southampton.

Plant, K. M., \& Sanders, M, R. (2007). Reducing problem behavior during care-giving in families of preschool-aged children with developmental disabilities. Research in Developmental Disabilities, 28(4), 362-385. doi: 10.1016/j.ridd.2006.02.009

Powers, M. B., Zum Vörde Sive Vörding, M. B., \& Emmelkamp, P. M. (2009). Acceptance and commitment therapy: A meta-analytic review. Psychotherapy and Psychosomatics, 78(2), 73-80. doi: 10.1159/000190790

Raes, F., Pommier, E., Neff, K. D., \& Van Gucht, D. (2011). Construction and factorial validation of a short form of the Self-Compassion Scale. Clinical Psychology \& Psychotherapy, 18 (3), 250-255. doi: 10.1002/cpp.702

Ree, M. J., \& Craigie, M. A. (2007). Outcomes following mindfulness-based cognitive therapy in a heterogeneous sample of adult outpatients. Behaviour Change, 24 (2), 70 86. doi: $10.1375 /$ bech.24.2.70

Shigaki, C. L., Glass, B., \& Schopp, L. H. (2006). Mindfulness-based stress reduction in medical settings. Journal of Clinical Psychology in Medical Settings, 13,209-216. doi: $10.1007 /$ s10880-006-9033-8 
Singer, G.H.S. (1993). When it's not so easy to change your mind: Some reflections on cognitive interventions for parents of children with disabilities. In A.P. Turnbull, J.M. Patterson, S.K. Behr, D.L. Murphy, J.G. Marquis, \& M.J. Blue-Banning (Eds.), Cognitive coping, families, and disability (pp. 207- 220). Baltimore: Paul H. Brookes.

Singer, G. H., Ethridge, B. L., \& Aldana, S. I. (2007). Primary and secondary effects of parenting and stress management interventions for parents of children with developmental disabilities: A meta-analysis. Mental Retardation and Developmental Disabilities Research Reviews, 13(4), 357-369. doi: $10.1002 /$ mrdd.20175

Singh, N. N., Lancioni, G. E., Winton, A. S. W., Fisher, B. C., Wahler, R. G., McAleavey, K., ... Sabaawi, M. (2006). Mindful parenting decreases aggression, non-compliance, and self-injury in children with autism. Journal of Emotional and Behavioral Disorders, 14(3), 169-177. doi: 10.1177/10634266060140030401

Singh, N. N., Lancioni, G. E., Winton, A. S. W., Singh, J., Curtis, W. J., Wahler, R. G., \& McAleavey, K. M. (2007). Mindful parenting decreases aggression and increases social behavior in children with developmental disabilities. Behavior Modification, 31(6), 749-771. doi: 10.1177/0145445507300924

Solomon, R., Necheles, J., Ferch, C., \& Bruckman, D. (2007). Pilot study of a parent training program for young children with autism: the PLAY project home consultation program. Autism, 11, 205-224. doi: 10.1177/1362361307076842

Sparrow, S., Balla, D. A. \& Cicchetti, D. (1984) Vineland Adaptive Behavior Scales (second edition). Minneapolis, MN: Pearson. 
Teasdale, J. D., Segal, Z. V., Williams, J. M. G., Ridgeway, V. A., Soulsby, J. M., \& Lau, M. A. (2000). Prevention of relapse/recurrence in major depression by mindfulnessbased cognitive therapy. Journal of Consulting and Clinical Psychology, 68(4), 615623. doi: 10.1037//0022-006X.68.4.615

Totsika, V., Hastings, R. P., Emerson, E., Berridge, D. M., \& Lancaster, G. A. (2011). Behavior problems at 5 years of age and maternal mental health in autism and intellectual disability. Journal of Abnormal Child Psychology, 39(8), 1137-1147. doi: 10.1007/s10802-011-9534-2

Totsika, V., Hastings, R. P., Emerson, E., Lancaster, G. A., \& Berridge, D. M. (2011). A population-based investigation of behavioural and emotional problems and maternal mental health: Associations with autism and intellectual disability. Journal of Child Psychology and Psychiatry, 52 (1), 91-99. doi:10.1111/j.14697610.2010.02295.x

Watson, D., Clark, L. A., Tellegen, A. (1988). Development and validation of brief measures of positive and negative affect: The PANAS scales. Journal of Personality and Social Psychology, 54 (6), 1063-1070. doi: 10.1037/0022-3514.54.6.1063

Weiss, J. A., Cappadocia, M. C., MacMullin, J. A., Viecili, M., \& Lunsky, Y. (2012). The impact of child problem behaviors of children with ASD on parent mental health: The mediating role of acceptance and empowerment. Autism, doi: $10.1177 / 1362361311422708$

Whittingham, K., Sofronoff, K., Sheffield, J., \& Sanders, M. R. (2009). Stepping Stones Triple P: an RCT of a parenting program with parents of a child diagnosed with an 
autism spectrum disorder. Journal of Abnormal Child Psychology, 37(4), 469-480. doi: $10.1007 / \mathrm{s} 10802-008-9285-\mathrm{x}$

Zigmond, A. S., \& Snaith, R. P. (1983). The hospital anxiety and depression scale. Acta Psychiatrica Scandinavica, 67(6), 361-370. doi: 10.1111/j.1600-

0447.1983.tb09716.x 
Table 1. Weekly Outline of Mindfulness Programme

\begin{tabular}{|c|c|c|c|}
\hline Session & Topic & Activities & Home Practice \\
\hline 1 & Automatic Pilot & $\begin{array}{l}\text { Introductions, ground rules; raisin meditation; breath in } \\
\text { body practice }\end{array}$ & $\begin{array}{l}\text { Breath in body practice; mindful eating; mindful } \\
\text { daily activity }\end{array}$ \\
\hline 2 & $\begin{array}{l}\text { Room to } \\
\text { Breathe }\end{array}$ & $\begin{array}{l}\text { Breath in body practice; reflection on home practice; body } \\
\text { scan; linking awareness of body, thoughts, emotions; } \\
\text { planting seeds of kindness }\end{array}$ & $\begin{array}{l}\text { Body scan; pleasant events diary; mindful daily } \\
\text { activity }\end{array}$ \\
\hline 3 & $\begin{array}{l}\text { Learning about } \\
\text { Stress }\end{array}$ & $\begin{array}{l}\text { Breath in body practice; reflection on home practice; } \\
\text { mindful movement practice; three step breathing space }\end{array}$ & $\begin{array}{l}\text { Mindful movement; unpleasant events diary; } \\
\text { notice stress reactions; three step breathing } \\
\text { space }\end{array}$ \\
\hline 4 & $\begin{array}{l}\text { Working with } \\
\text { Stress }\end{array}$ & $\begin{array}{l}\text { Mindful movement practice; reflection on home practice; } \\
\text { three step breathing space; learning about affect systems; } \\
\text { awareness of breath practice }\end{array}$ & $\begin{array}{l}\text { Awareness of breath practice; daily activity to } \\
\text { care for self/nurturing activity; use three step } \\
\text { breathing space when needed }\end{array}$ \\
\hline 5 & $\begin{array}{l}\text { Responding to } \\
\text { Difficulties }\end{array}$ & $\begin{array}{l}\text { Awareness of breath practice; exploring difficulty; learning } \\
\text { to respond rather than react; mindful movement } \\
\text { practice; three step breathing space }\end{array}$ & $\begin{array}{l}\text { Awareness of breath practice; sounds and } \\
\text { thoughts practice; three step breathing space } \\
\text { when needed; nurturing activity }\end{array}$ \\
\hline 6 & $\begin{array}{l}\text { Communicatio } \\
\mathrm{n}\end{array}$ & $\begin{array}{l}\text { Sitting practice; reflection on home practice; movement } \\
\text { practice; mindful listening practice; discussing patterns } \\
\text { of communication }\end{array}$ & $\begin{array}{l}\text { Awareness of breath practice; three step } \\
\text { breathing practice when needed; nurturing } \\
\text { activity; noticing communications }\end{array}$ \\
\hline 7 & $\begin{array}{l}\text { Living our } \\
\text { Lives }\end{array}$ & $\begin{array}{l}\text { Sitting practice; reflection on home practice; movement } \\
\text { practice; discussing values; }\end{array}$ & $\begin{array}{l}\text { Participants to choose which practices off the CD; } \\
\text { nurturing activity; three step breathing space } \\
\text { when needed }\end{array}$ \\
\hline 8 & $\begin{array}{l}\text { Rest of our } \\
\text { Lives }\end{array}$ & $\begin{array}{l}\text { Sitting practice; reflecting on home practice; discussing how } \\
\text { to continue with practices; movement practice }\end{array}$ & Plan for continued mindful practice \\
\hline
\end{tabular}


Table 2. Mean Scores, Within-Groups Comparisons, and Effect Sizes of Changes in Scores on all Measures between Time 1 and Time 2.

\begin{tabular}{lcccccccc}
\hline Measure & T1 mean & SD & T2 mean & SD & $t$ value & df & $p$ value & $d$ value \\
\hline Process Measures & & & & & & & & \\
$\quad$ Mindfulness & 115.84 & 21.10 & 125.00 & 15.87 & -3.00 & 18 & .008 & 0.49 \\
$\quad$ Mindful Parenting & 27.40 & 5.68 & 26.80 & 5.07 & .54 & 19 & .594 & 0.11 \\
Acceptance & 42.76 & 8.80 & 42.24 & 7.44 & .25 & 20 & .802 & 0.06 \\
$\quad$ Self-compassion & 30.30 & 8.81 & 33.50 & 7.49 & -2.22 & 19 & .039 & 0.39 \\
Well-Being Measures & & & & & & & & \\
$\quad$ Anxiety & 11.55 & 3.62 & 10.55 & 4.02 & 1.13 & 19 & .204 & 0.26 \\
$\quad$ Depression & 6.75 & 3.08 & 6.10 & 3.14 & .76 & 19 & .459 & 0.21 \\
$\quad$ General Stress & 12.74 & 4.27 & 10.53 & 4.75 & 2.35 & 18 & .031 & 0.49 \\
$\quad$ Positive Affect & 33.85 & 7.94 & 33.20 & 9.51 & .29 & 19 & .777 & 0.07 \\
$\quad$ Child Related Stress & 6.81 & 4.12 & 7.31 & 4.19 & -.739 & 15 & .472 & 0.12 \\
$\quad$ Positive Gain & 13.47 & 3.60 & 12.43 & 4.38 & 1.49 & 20 & .151 & 0.31 \\
Child Measure & & & & & & & & .835 \\
$\quad$ Prosocial behaviour & 4.65 & 3.34 & 4.80 & 4.07 & -.211 & 19 & 0.04 \\
$\quad$ Behaviour Problems & 24.74 & 7.81 & 25.95 & 9.10 & -1.02 & 18 & .321 & 0.14 \\
\hline
\end{tabular}


Table 3. Parent Ratings of Satisfaction with Different Aspects of the MBW-P Course.

\begin{tabular}{lccc}
\hline \multicolumn{1}{c}{ Aspect of course } & $\begin{array}{c}N \text { satisfied or } \\
\text { very satisfied }\end{array}$ & $\begin{array}{c}\text { N neither } \\
\text { satisfied nor } \\
\text { dissatisfied }\end{array}$ & $\begin{array}{c}N \text { dissatisfied } \\
\text { or very } \\
\text { dissatisfied }\end{array}$ \\
\hline Location & 19 & 2 & 0 \\
Demand on time & 19 & 1 & 1 \\
Support during class & 20 & 0 & 1 \\
Support between classes & 18 & 2 & 1 \\
Benefitted from attending & $N$ definitely agree & N not sure & $N$ not agree \\
Continue with practices & 20 & 1 & 0 \\
Recommend to others & 16 & 5 & 0 \\
\hline
\end{tabular}

